\title{
An unusual cause of traumatic spinal cord injury: Case report
}

\author{
DM Clinchot and SC Colachis III \\ Department of Physical Medicine And Rehabilitation, The Ohio State University, College of Medicine, Columbus, \\ Ohio, USA
}

\begin{abstract}
Traumatic spinal cord injuries occurring after cardiac arrest are rare. In such cases, injury to the cervical cord may result from the intubation of a patient during resuscitation. We report a very unusual case where cardiac arrest occurring during cardiac rehabilitation resulted in an unexpected traumatic cervical spinal cord injury.
\end{abstract}

Keywords: cervical spinal cord injury; cardiac arrest; cardiac rehabilitation

\section{Introduction}

Cardiac arrest is rarely associated with spinal cord injury. In such cases, injury to the spinal cord can result from cord ischemia from vascular insufficiency. ${ }^{1}$ Traumatic injuries are very rare but can result from hyperextension of the neck during intubation. ${ }^{2}$

We report an unusual case of traumatic cervical spinal cord injury occurring after an acute cardiac arrest during cardiac rehabilitation which was unrelated to treatment during resuscitation efforts.

\section{Case report}

In September 1993, a 63 year old man was exercising on a treadmill during a cardiac rehabilitation program when he developed sudden weakness, dizziness, and diaphoresis. He fell off the treadmill and struck his forehead on a wall causing an indentation in the plasterboard. He was noted at that time to have a cardiac arrest with ventricular tachycardia. He was successfully cardioverted and regained consciousness; intubation and ventilatory support were not required. Upon regaining consciousness, he complained of upper and lower limb weakness.

He was transferred as an emergency patient to our medical center where he was evaluated and subsequently had an internal cardiac defibrillator implanted. Study of his persistent weakness revealed a herniated disk at the C6/C7 level (Figure 1). He underwent an anterior cervical decompression operation two weeks following the spinal injury, and shortly thereafter, was discharged home with a cervical orthosis.

For the next several weeks, he continued to have difficulty with upper and lower limb weakness. Repeat myelography demonstrated subluxation of C6 on C7 vertebra of approximately one third of the vertebral body. He was placed in Gardner-Wells tongs with

Correspondence: Daniel M Clinchot, M.D. improvement in alignment at $\mathrm{C} 6 / \mathrm{C} 7$. He subsequently underwent posterior cervical reduction, fusion with iliac bone graft, and lateral mass fixation a month later. His subsequent hospital course was complicated by the development of rapidly progressive neurological

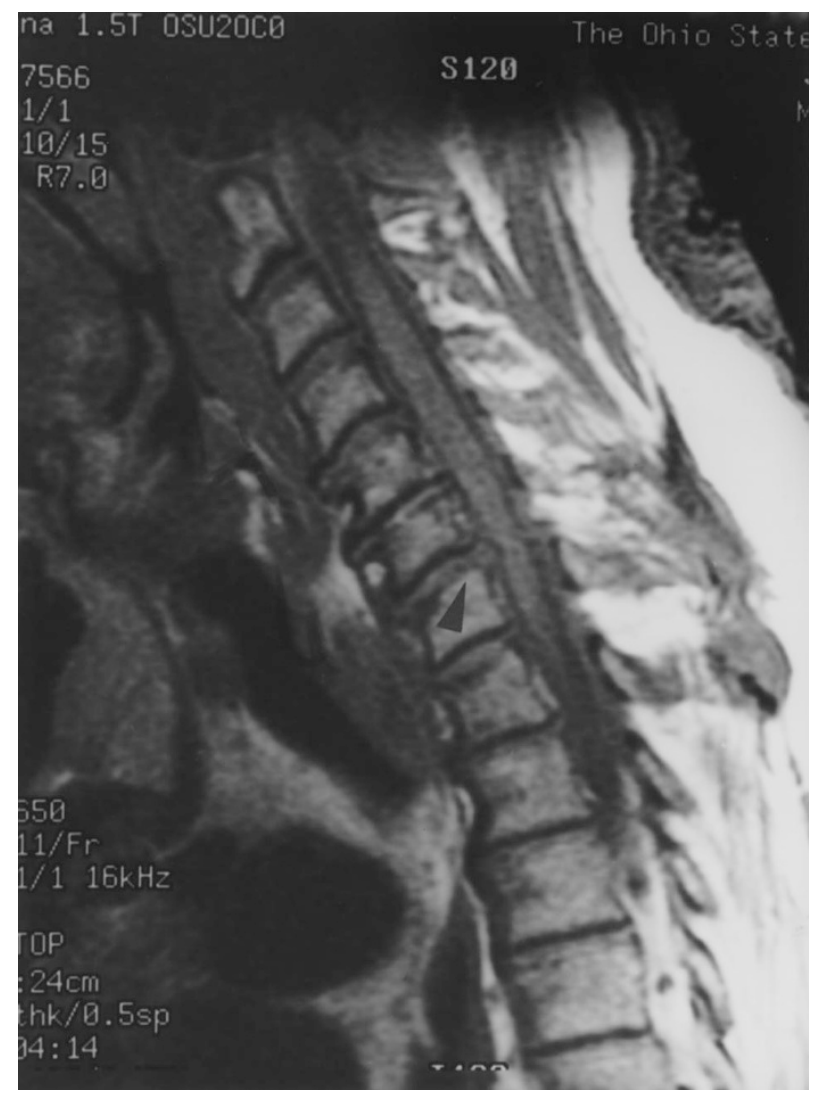

Figure 1 T1-weighted Magnetic Resonance Imaging (MRI) at the level of the cervical spine (sagital view). MRI showing a herniated disc at the $\mathrm{C} 6 / \mathrm{C} 7$ level (black arrow) 
deterioration with a significant $\mathrm{C} 7$ incomplete tetraplegia (ASIA Impairment Scale 'C') associated with bladder and bowel dysfunction. Myelography revealed a complete myelographic block at $\mathrm{C} 7 / \mathrm{T} 1$ with the appearance of epidural compression. The thecal sac and spinal cord compression were seen at C5/C6 and $\mathrm{C} 6 / \mathrm{C} 7$ on post-myelogram CT scanning. He had an emegerncy C6-T1 total laminectomy and partial C5 laminectomy with removal of lateral mass fixation, and application of additional fixation just over a month later.

His condition stabilized and he was transfered to our spinal cord rehabilitation unit 9 days later. His neurological status and functional independence improved considerably and by the time of discharge home 18 days later, he was able to walk several thousand feet. Two years later, he continues to have normal bladder and bowel function, and normal lower limb function except for minimal knee and ankle weakness, mild right arm and forearm weakness, and moderate right hand intrinsic weakness.

\section{Discussion}

The present case illustrates a very unusual event resulting in traumatic cervical spinal cord injury. Our patient had a cardiac arrest associated with trauma to his cervical spine. Although injuries to the cervical spinal cord can occur when the head forcibly impacts a stationary structure such as a wall, we are presently unaware of any similar reports in the literature describing such an unusual circumstance associated with traumatic myelopathy. It is interesting to speculate as to the sequence of events in the present case.

Our patient was in cardiac arrest with documented ventricular tachycardia after having fallen off a treadmill during an exercise program. One would infer from this presentation that he had a primary cardiac event resulting in loss of consciouness, a fall from the treadmill, and an injury to his cervical spine. Although this is the most likely explanation, the cardiac arrest may have followed the cervical injury. The patient may have become lightheaded, lost his balance and fell while conscious, striking the wall and sustaining a cervical spinal cord injury. The cardiac arrest may have been subsequent to that injury. Acute cervical spinal cord injuries produce significant alterations in autonomic nervous system activity ${ }^{3}$ and cardiac arrest has been reported shortly following the injury. ${ }^{4}$ Our patient had significant cardiac disease associated with arrhthymias and any profound alteration in sympathetic function might exacerbate that condition.

Trauma to the neck and cervical spine can occur during the intubation of a patient ${ }^{2}$ and special care is required when intubating patients who have conditions which could increase their risk for injury (eg cervical factures, ${ }^{5}$ traumatic or atraumatic cervical instability ${ }^{2}$ ). Our patient was not intubated during resuscitation of the cardiac arrest. Vascular insufficiency and ischemic myelopathy can also result during cardiac arrest, ${ }^{1}$ although this is quite uncommon. Given the clinical presentation of our patient, a traumatic etiology was the only consideration.

We feel that a primary cardiac event lead to our patient's loss of consciousness and the subsequent traumatic spinal cord injury. His history of significant coronary artery disease associated with arrhythmias supports this hypothesis. It is of interest to note that recently the patient reported that this implanted defibrillator discharged without complication.

\section{References}

1 Imaizumi H, Ujike Y, Kaneko M, Chiba S. Spinal cord ischemia after cardiac arrest. J Emergency Med 1994; 12: 789 - 793.

2 Barron M. Cervical spine injury masquerading as a medical emergency. Am J Emergency Med 1989; 7: 54-56.

3 Mathias C, Frankel HL. Clinical manifestations of malfunctioning sympathetic mechanisms in tetraplegia. J Autonomic Nerv System 1983; 7: 303-312.

4 Lehmann KG, Lane JG, Piepmeier JM, Batsford WP. Cardiovascular abnormalities accompanying acute spinal cord injury in humans: incidence, time course and severity. $\mathrm{J} \mathrm{Am}$ College Cardiology 1987; 10: 46- 52.

5 Kellman R. The cervical spine in maxillofacial trauma: assessment and airway management. Otolaryngol Clin $N \mathrm{Am}$ 1991; 24: $1-13$ 